\title{
A Review of Desiccant Dehumidification Technology
}

Ahmad A. Pesaran

National Renewable Energy Laboratory

Prepared for Proceedings of EPRI's Electric Dehumidification: Energy Efficient Humidity Control for Commercial and Institutional Buildings Conference, New Orleans, Louisiana June 2-3, 1993

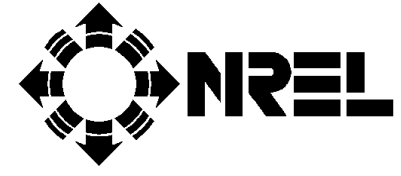

National Renewable Energy Laboratory 1617 Cole Boulevard Golden, Colorado 80401-3393

A national laboratory of the U.S. Department of Energy Managed by Midwest Research Institute for the U.S. Department of Energy under contract No. DE-AC36-83CH10093

October 1994 


\section{NOTICE}

This report was prepared as an account of work sponsored by an agency of the United States government. Neither the United States government nor any agency thereof, nor any of their employees, makes any warranty, express or implied, or assumes any legal liability or responsibility for the accuracy, completeness, or usefulness of any information, apparatus, product, or process disclosed, or represents that its use would not infringe privately owned rights. Reference herein to any specific commercial product, process, or service by trade name, trademark, manufacturer, or otherwise does not necessarily constitute or imply its endorsement, recommendation, or favoring by the United States government or any agency thereof. The views and opinions of authors expressed herein do not necessarily state or reflect those of the United States government or any agency thereof.

Available to DOE and DOE contractors from:

Office of Scientific and Technical Information (OSTI)

P.O. Box 62

Oak Ridge, TN 37831

Prices available by calling 423-576-8401

Available to the public from:

National Technical Information Service (NTIS)

U.S. Department of Commerce

5285 Port Royal Road

Springfield, VA 22161

703-605-6000 or 800-553-6847

or

DOE Information Bridge

http://www.doe.gov/bridge/home.html 


\title{
A REVIEW OF DESICCANT DEHUMIDIFICATION TECHNOLOGY
}

\author{
Ahmad A. Pesaran \\ National Renewable Energy Laboratory \\ Golden, Colorado \\ Prepared for Proceedings of \\ Electric Dehumidification: Energy Efficient Humidity Control \\ for Commercial and Institutional Buildings Conference, \\ sponsored by the Electric Power Research Institute, \\ New Orleans, Louisiana, June 2-3, 1993
}

\begin{abstract}
This paper overviews applications of desiccant technology for dehumidifying commercial and institutional buildings. Because of various market, policy, and regulatory factors, this technology is especially attractive for dehumidification applications in the 1990s. After briefly reviewing the principle of operation, we present three case studies-for supermarkets, a hotel, and an office building. We also discuss recent advances and ongoing research and development activities.
\end{abstract}

\section{INTRODUCTION}

The heating, ventilation, and air conditioning (HVAC) industry is facing several challenges in the 1990 s, including a decrease of energy resources, an increase in energy demand due to population growth, and new regulatory policies. To respond to these challenges, more energy-efficient heating, cooling, ventilation, and dehumidification technologies are needed. However, there are a number of constraints for deployment of energy-efficient HVAC technologies; among them are the imminent phase-out of chlorofluorocarbons (CFCs), eventual phase-out of hydrochlorofluorocarbons (HCFCs), and the increase in ventilation rates for buildings because of concerns regarding indoor air quality and occupant health. The higher ventilation rates translate into greater cooling loads-in particular, greater latent loads-during cooling seasons when the relative humidity within a building must be kept sufficiently low to inhibit the growth of micro-organisms that cause health problems and also may damage building materials. As a result, air dehumidification has become a very important part of the HVAC function. Desiccant dehumidification and cooling technology can provide energy-efficient solutions for the industry. Desiccant dehumidification technology has a successful track record over more than 60 years for industrial applications such as product drying and corrosion prevention. It has also been used for many years in clean rooms, hospitals, museums, and other special cases requiring highly controlled humidity levels. Milton Meckler has recently discussed various benefits of the desiccant technology, its potential applications, and factors that drive its future growth (AGCC, 1994).
In recent years, the use of desiccants for dehumidification in air-conditioning applications has been on the rise (see Figure 1), and their capital cost has been on the decline. The supermarket industry was the first to realize the potential of desiccant dehumidification, and there are currently more than 500 supermarkets that use desiccant dehumidification packages integrated with electric-driven refrigeration systems (Harriman, 1994). In these integrated designs, the desiccant system works as a pre-conditioner for outside (ventilation) air to remove the latent load. Other applications of desiccant dehumidification are in ice rinks, hotels and motels, office buildings, full-service and fast food restaurants, medical facilities, and retirement homes. The benefits of desiccant dehumidification are better humidity control, more efficient latent load removal, and reduction of peak electric demands. In regions of the country where the electric utilities are having trouble servicing their peak air-conditioning loads, this energy-efficient technology can assist in meeting that demand.

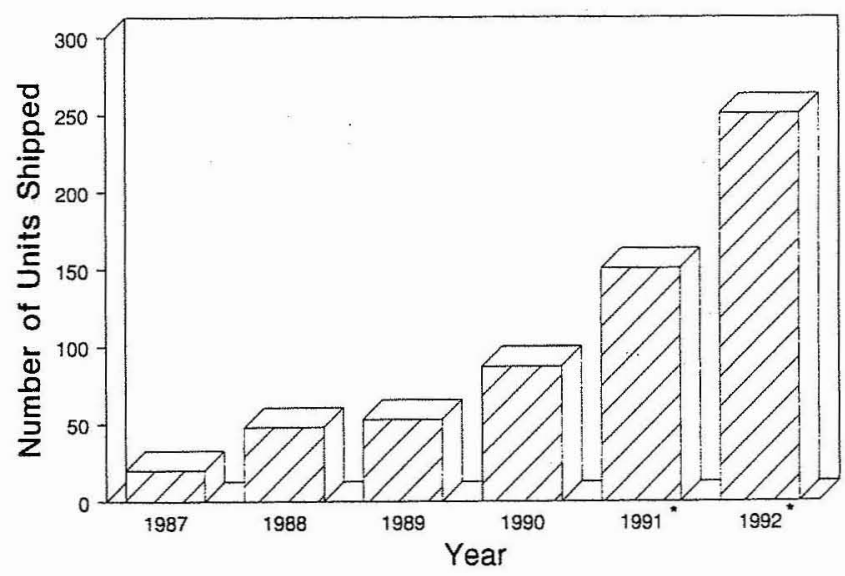

Figure 1. Recent Growth Trend for the Desiccant Dehumidification Equipment Market, from EPRI (1992), except for 1991 and 1992, which are estimates based on discussions with two manufacturers. 


\section{DESICCANT DEHUMIDIFICATION TYPES}

Air dehumidification can be achieved by two methods: (1) cooling the air below its dew point and removing moisture by condensation, or (2) sorption by a desiccant material. Desiccants in either solid or liquid forms have a natural affinity for removing moisture. As the desiccant removes the moisture from the air, desiccant releases heat and warms the air, i.e., latent heat becomes sensible heat. The dried warm air can then be cooled to desired comfort conditions by sensible coolers (e.g., evaporator coils, heat exchangers, or evaporative coolers.). To re-use the desiccant, it must be regenerated or reactivated through a process in which moisture is driven off by heat from an energy source such as electricity, waste heat, natural gas, or solar energy.

For industrial applications, solid desiccant cycles use dual-column packed-bed dehumidifiers; however, the most appropriate dehumidifier configuration for air-conditioning applications is the rotary wheel (see Figure 2). The air to be dehumidified enters the system, comes into contact with the desiccant wheel, and exits the dehumidifier hot and dry. The wheel is then rotated so that the desiccant portion that has picked up moisture is exposed to hot reactivation air and its moisture removed.

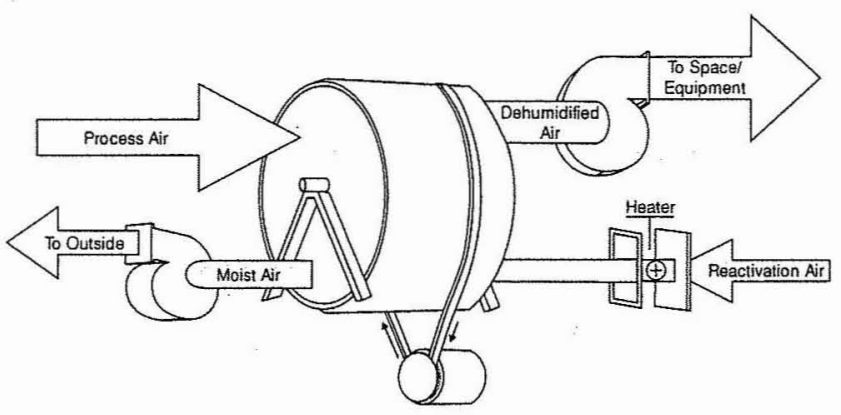

Figure 2. Solid-Desiccant-Wheel Dehumidifier (Munters Cargocaire)

Since the air leaving the desiccant is heated because of the release of heat adsorption, there is a need for cooling the dried air in cooling applications. This can be accomplished with a sensible heat exchanger such as a heat pipe or with a standard vapor-compression cooling coil. Figure 3 shows schematics of a desiccant air conditioner incorporating direct-evaporative coolers and a rotary solid-desiccant wheel.

Figure 4 is a schematic of a liquid-desiccant dehumidification system. In a liquid system, there are two separate chambers-one to perform the dehumidification (or conditioning) and the other to reactivate (or regenerate) the desiccant. The processed air from the dehumidification chamber enters into the conditioned space. The desiccant, leaving the dehumidification chamber containing absorbed moisture, goes through a heat exchanger and down to the regenerator, where heat is added to remove the moisture. The liquid desiccant is pumped continually between the two chambers when dehumidification is needed.

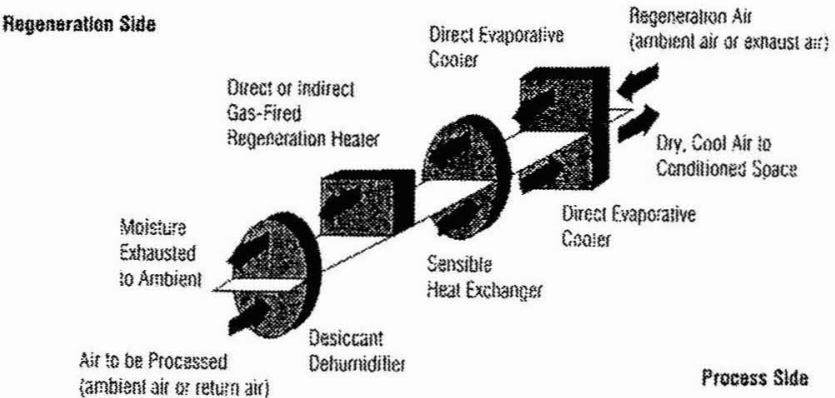

Figure 3. Schematic of a Solid-Desiccant Air Conditioner (GRI, 1992)

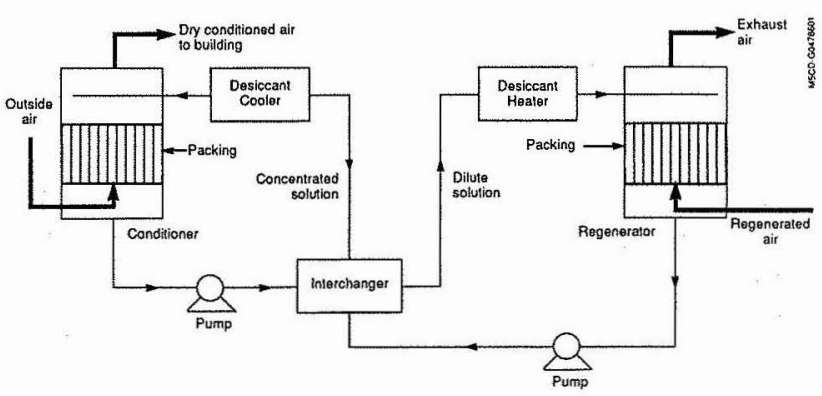

Figure 4. Schematic of a Liquid-Desiccant Dehumidification System

Pesaran et al. (1992) provide a complete report with approximately 900 citations on various desiccant cooling cycles and past research and development. An excellent tutorial on psychometrics, methods of dehumidification, and many applications are presented in a dehumidification handbook by Harriman (1990). A special ASHRAE publication (ASHRAE, 1992) contains a collection of papers on desiccant system applications, low-level humidity control, and moisture load calculations.

\section{DESICCANT DEHUMIDIFICATION APPLICATIONS}

Desiccant systems are especially useful when the latent load is high (i.e., when the latent-to-sensible heat ratio is high), because they remove moisture more economically than they remove sensible heat. Another desirable situation is when the cost of dehumidification with a desiccant is lower than the cost of dehumidification with a refrigeration system. This is where thermal energy comes into the picture: there are instances where desiccant regeneration done by waste heat, natural gas, or off-peak electricity is more economical compared to regular electric refrigeration. Because there is no need for reheating with desiccant dehumidification systems, another appropriate use is when conditioned air must be reheated after coming out of a coil to reach a comfortable dry-bulb temperature. Finally, the use of a desiccant is well-suited to the case where dehumidification is required at levels below freezing dew-point temperatures. For example, an ice arena has is a great deal of humidity, but the cooling coil has to cool below the freezing point. In such an environment, dehumidification with desiccants can play a major role. 
Taking into consideration these "best" circumstances, several sectors of the market have characteristics to be good marketing opportunities for desiccant dehumidification. Supermarkets have provided the best opportunity. Ice rinks, hotels and motels, and retail stores have dehumidification needs that could be met very efficiently with desiccants. Restaurants have provided another opportunity for desiccants because of high ventilation-rate requirements and high moisture levels generated by cooking. Office buildings could use desiccants because of high ventilation-rate requirements in response to the "sick building syndrome" and the ASHRAE Standard 62-89 on indoor air quality; office buildings in regions with high humidity (high latent load) are especially good candidates. Hospitals and nursing homes have been using liquid-desiccant systems for many years.

In the following sections, we will review three applications using desiccant dehumidification and will then provide an overview of recent development activities.

\section{Supermarket Applications}

The rise in supermarket applications has resulted in the continuous increase in the number of desiccant dehumidification units shipped during the last several years (see Figure 1).

Problem Definition-In supermarkets, conventional refrigeration systems tend to cycle on and off, which allows build-up of humidity and frost. A conventional air-conditioning system that handles both loads is not very efficient because there may be a need for reheat. And because the cooling coils must be at a temperature below dew point to allow for condensation, the coefficient of performance (COP) or energy efficiency ratio (EER) of the refrigeration system is not very high. If the humidity could be controlled independently of temperature, supermarkets would be more comfortable and the maintenance due to frost on freezer cases (a cost problem to supermarkets) would be eliminated.

Solution-A more efficient means is to use a gas-fired desiccant module to handle the latent load and a downsized electric vapor-compression refrigeration system to take care of the sensible load. This allows

- the evaporator to have a higher temperature, so the EER (the refrigeration $\mathrm{COP}$ ) will rise;

- $\quad$ separate control of humidity and temperature;

- potential for energy cost savings through

- reducing refrigeration COP and the energy cost of defrost and anti-sweat heaters, and

- circulating less air because drier air has more dehumidification capacity.

The principle of splitting the sensible and latent loads is used in desiccant equipment for supermarket applications. Figure 5 is a schematic of one of the latest supermarket desiccant dehumidification systems-the SuperAire system from Munters DryCool. In the last several years since its development, the system has undergone several improvements including the use of a heat-pipe heat exchanger instead of an air-to-air heat exchanger and the replacement of a lithium chloride wheel with a silica gel wheel. DESI/AIR desiccant systems manufactured by ICC Technologies have also been installed in many supermarkets with resultant energy cost savings.

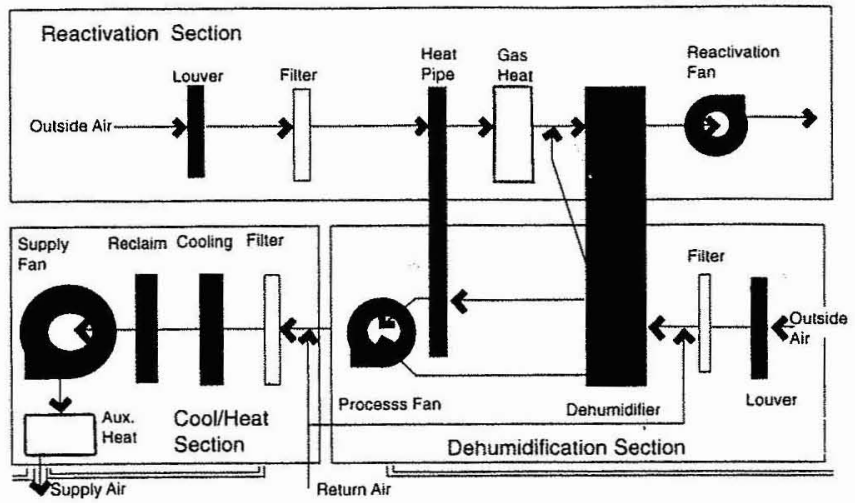

Figure 5. Schematic of the Munters SuperAire System for Supermarket Dehumidification (Munters DryCool)

Example Result-In one example, a SuperAire dehumidification and cooling system helped a Shaw's supermarket in New England to realize energy cost savings of $\$ 8,500 / y$ ear with a simple payback of less than 3 years. A rebate from the local gas utility lowered the payback to under 2 years (GRI, 1994). Using desiccant systems, stores provide a drier, more comfortable store environment for shoppers and employees, while extending product shelf life and reducing frost buildup on frozen products and refrigerated cases.

\section{Hotel Case Study}

Problem Definition - Mold, mildew, and musty odors are problems in many hotels, and especially in humid climates, costing members of the American Hotel and Motel Association over $\$ 68$ million each year (AHMA, 1991). Carpet and wallpaper must often be removed because trapped humidity causes mold and mildew to grow on the back surfaces. Mold and mildew are forms of fungus whose growth and reproduction create the familiar musty odor we smell in damp rooms and humid climates. Fungus growth may be eliminated in three ways: kill the fungus, remove its food, or remove its water (humidity). Removing excessive moisture from materials is usually the most practical and effective means of stopping mold and mildew. Air humidity must be controlled below $60 \%$ relative humidity $(\mathrm{RH})$ to avoid the growth of mold and mildew.

One hotel in West Palm Beach, Florida-a small three-story building with 150 rooms in two wings-had problems with indoor moisture. Only 1 year after opening, two-thirds of the rooms were experiencing mold and mildew and were either undergoing repairs or had already undergone major repair such as removal of the carpet and wallpaper; the ceiling gridwork in corridors was also 
rusting (Banks, 1992). The existing HVAC system consists of a 25-ton split system for each wing, supplying about $5000 \mathrm{scfm}$ air through a ceiling plenum. The guest rooms had individual 1-ton packaged terminal air-conditioner units.

Remedial Measures-In an attempt to improve dehumidification, the HVAC system on the north wing was retrofitted with a desiccant module (Banks, 1992). In the north wing, a desiccant system was installed as an add-on to the existing vapor-compression system, with the addition of more capacity to dehumidify the wing. The south wing maintained its conventional cool/reheat system using vapor-compression equipment, but the air distribution system was changed, using more air volume in each wing $(6000 \mathrm{scfm})$ and a positive air pressure in the building to reduce air infiltration. The two wings were instrumented and monitored for 9 months.

Results-The cool/reheat equipped south-wing moisture problems were improved by operating under humidistat control, but the odor still existed and the rust on ceiling tile reappeared (Banks, 1992). The north-wing condition showed much more improvement than the south wing, having lower humidity and no recurrence of musty odors after several weeks. Figure 6 compares moisture level in cavities behind the walls of the south wing and the north wing. In the north wing's first floor, the moisture in the wallboard measured 13 on the Delmhorst reference scale compared to 20 in the south wing-a trend which held throughout the other floors. The average humidity level in the wall cavity was $60 \% \mathrm{RH}$ on the wing with the desiccant system, whereas the wall cavities on the cool/reheat wing experienced average humidity of $69 \% \mathrm{RH}$. According to microbiologists, significant mold/mildew problems can occur when humidity levels exceed $65 \% \mathrm{RH}$. The first floor of the two wings is connected by a restaurant and a lobby, and some of the moisture from the south side may have entered the north side. On the desiccant side, the humidity problem on the second and third floors disappeared after a few months of testing, and the rust on the ceiling-tile grid was also eliminated.

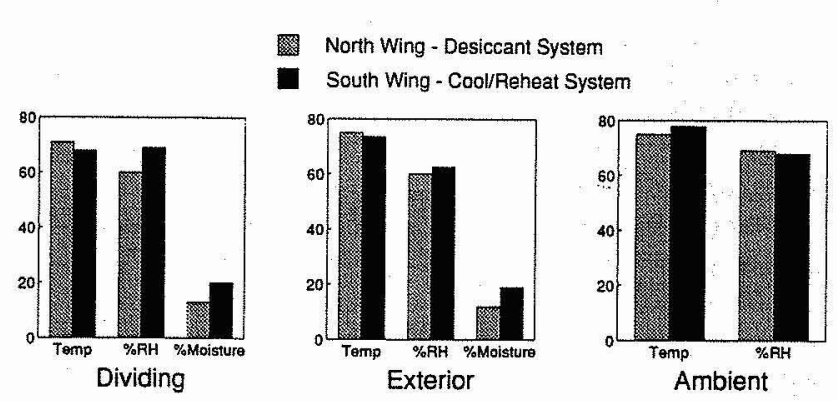

Figure 6. Average Moisture in the Wall Cavity, North Wing versus South Wing, November 1990-July 1991, for a Three-Story Hotel (Banks, 1992)

Another item examined was the amount of fungal samples found in the two wings. The count of fungi in the desiccant wing was about one-fourth of that in the cool/reheat wing-a very encouraging result. According to a computer model based on the obtained test data at this location, a properly sized cool/reheat system can cost more to operate than a gas-fired desiccant module plus a downsized cooling system. In this building, the total installed direct-expansion tonnage for conditioning outside air could be reduced by $40-50$ tons by using a desiccant module-a reduction of more than $50 \%$. A desiccant system could reduce peak demand, which is an important factor in areas where the peak-demand electric charges are high. In this particular application, the hotel could achieve a $\$ 3,000$ energy savings annually over the cool/reheat system (Banks, 1992). Currently, a desiccant system does have a higher initial cost, but the life-cycle cost must be considered, including avoided repair costs, as well as the benefits of lower humidity in the walls and improved customer comfort.

\section{Office Building Case Study}

Problem Definition-The new requirements of revised ASHRAE Standard 62-89, "Ventilation for Acceptable Indoor Air Quality," call for outside-air ventilation rates of 3-4 times the current practice, thus increasing the latent load. Most variable air volume (VAV) all-air systems do not meet the ASHRAE standard under certain load conditions during much of the year (Meckler, 1993). In addition, CFC refrigerant production will be banned by 2000 , and commonly used CFC refrigerants are expected to soar in price. Chiller conversion to replace these refrigerants sooner will become an important issue to building managers, but the switch to non-CFC refrigerants may reduce the capacity of the chillers. These issues (increased ventilation rates and $\mathrm{CFC}$ replacement) must be addressed and the HVAC systems in many office buildings will have to be retrofitted and new systems added. This situation provides an opportunity for desiccants to precondition the ventilation air, rather than dealing with the addition of a new conventional system. In some areas of the country, this change will actually save energy costs.

Figure 7 shows a schematic of an existing all-air VAV system located in a six-story, 346,600 sq- $\mathrm{ft}$ Houston office building (Meckler, 1993). The current HVAC system with 1000 tons of capacity provides $0.1 \mathrm{cfm}$ per square foot of outdoor air based on $143 \mathrm{sq} \mathrm{ft}$ per person and $15 \mathrm{cfm}$ per person. If the ventilation rate is increased to $20 \mathrm{cfm} /$ person, in accordance with ASHRAE 62-89 with $100 \mathrm{sq} \mathrm{ft}$ per person, then the cooling load will increase to about 1347 tons. If the chiller is converted to HCFC use, its capacity may drop to 850 tons.

Retrofit Options-To meet the higher cooling load of 1347 tons, Meckler (1993) studied two retrofit options. The first option was to add another chiller with 498-ton capacity to handle the increased ventilation rates and $\mathrm{HCFC}$ replacement. The second retrofit option was to add a desiccant system to the existing HCFC-converted 850-ton chiller to take care of the increased ventilation rate (see Figure 8).

A two-stage desiccant preconditioner system with an enthalpy wheel (a total heat exchanger) and a desiccant wheel was proposed. The enthalpy wheel preconditions the outside air before it goes to the desiccant dehumidifier, removing some moisture and 
sensible load to reduce the amount of regeneration energy needed; regeneration of the enthalpy wheel was done by outside air. In the desiccant portion, the air is dried deeply. The energy for regeneration can be provided by an air-to-air heat exchanger, waste heat from the system, and natural gas. According to Meckler (1993), the average annual thermal COP for this system in Houston weather conditions was 2.19, ranging between 1.2 and 3.3. In this second option, the desiccant preconditioner removed 566 tons of cooling, with 781 tons handled by the HCFCconverted chiller.

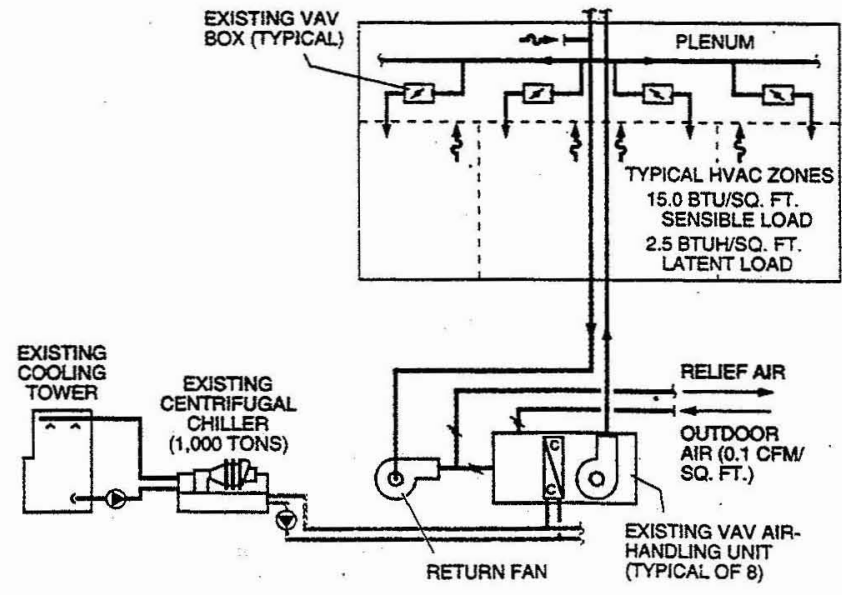

Figure 7. Schematic of an Existing All-Air VAV System of an Office Building in Houston, Texas (Meckler, 1993)

Energy Costs Savings-Retrofit 1 uses electricity and retrofit 2 uses both gas and electricity. The economics of retrofit 1 versus retrofit 2 depend on location, so the local utility's rate structure must be considered. In Houston, utility rates are about $\$ .087 / \mathrm{kWh}$ and $\$ 4.25 / \mathrm{MBtu}$ gas. In this particular example, Meckler (1993) included the following energy costs:

- For the existing system (which cannot meet the requirement because it supplies only $0.1 \mathrm{cfm} / \mathrm{sq}-\mathrm{ft}$ ), the annual energy cost was $\$ 196,400$.

- For retrofit 1 (all vapor-compression chilling), the annual energy cost was $\$ 232,500$.

- For retrofit 2 (the gas-fired desiccant system plus the existing chiller) the annual energy cost was $\$ 205,400$.

In this Houston application, the desiccant option resulted in a $\$ 27,100$ annual saving in energy costs over vapor-compression chilling.

\section{RECENT DESICCANT DEHUMIDIFICATION TECHNOLOGIES}

Although desiccant dehumidification is cost-effective for some niche-market application, the first-cost of desiccant systems is still high for broad air-conditioning applications. In this section, we will review recent developments in desiccant dehumidification technology intended to improve cost-effectiveness and performance.

For many years, the Gas Research Institute (GRI) has been supporting the development of desiccant technology for air-conditioning applications. The GRI program has already produced the well-received product, SuperAire, for supermarkets. In 1992-1993, the main thrust of the GRI program was to develop lower-cost, higher-performance desiccant wheels, to develop design and analysis tools, and to generate data and information. GRI has focused on cost-effective niche-market initiatives such as supermarkets, and recently, hotels and motels. Laroche Chemical and Semco Manufacturing have been working with GRI to develop dehumidifiers based on a new class of desiccant called Type 1M. Laroche Chemical's Type $1 \mathrm{M}$ wheel is very efficient for moisture removal and regeneration at $350^{\circ}-400^{\circ} \mathrm{F}$ and requires a gas-fired system to provide the desired regeneration temperatures. GRI has also been exploring residential applications with Hermidifier $\mathrm{Co}$, which has developed a water-heaterpowered desiccant dehumidifier. Munters DryCool and GRI have been working to develop and test desiccant make-up air systems for hotels and motels.

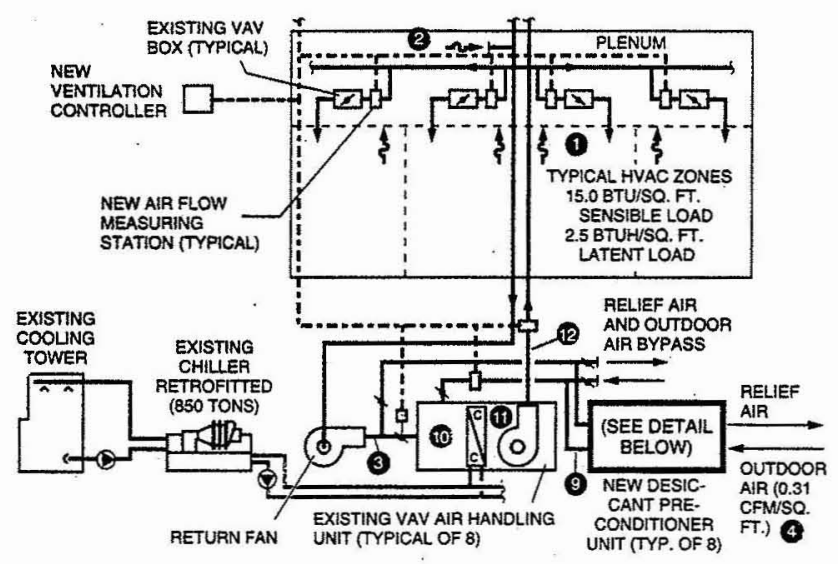

TWO-STAGE DESICCANT PRECONDITIONER

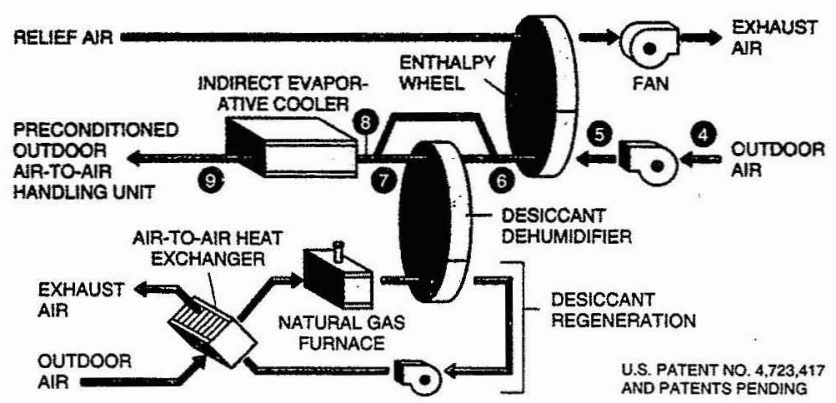

Figure 8. Houston All-Air VAV System Retrofitted with a Desiccant Preconditioning System (Meckler, 1993)

ICC Technologies, Inc., manufactures single factory-package systems that provide desiccant dehumidification. Some of their systems (e.g., the DESI/AIR models) that use evaporative coolers provide cooling and have been installed in supermarkets and other 
retail stores. ICC will also be producing a smaller version, Desert Cool, for small commercial and residential applications. ICC is working with Engelhard Corporation to produce a dehumidifier based on a family of desiccant materials called ETS, which is suitable for low-temperature applications. One form of ETS (Engelhard Titanium Silicate) desiccant could be regenerated at less that $140^{\circ} \mathrm{F}$, so waste heat from condensing units of electric chillers could be used. Figure 9 shows ICC's DESI/AIR System which has a desiccant wheel, heat-exchanger wheel, and evaporative cooling pads, and can be used as a preconditioner for ventilation air. One of these units will be installed in a J.C. Penney store in White Plains, New York, which currently has a two-chiller HVAC system. The first chiller is usually sufficient for meeting the sensible load, so the second chiller seldom is required during the day. However, the store experiences a peak cooling demand at 9:00 a.m. because of residual moisture from overnight, prompting the second chiller to run with a high $\mathrm{kW}$ demand. Instead of operating the second chiller, the addition of the DESI/AIR System to the first chiller is expected to eliminate the need for the other, and thus, will eliminate about $140 \mathrm{~kW}$ of demand.

A number of other organizations are also working on desiccant research and development:

- Albers Air Conditioning Corporation is looking at liquid-desiccant air conditioners as a single-package system.

- An analytical comparison showed that the DEAC's energy-efficiency-ratio values at low sensible-heat ratios are higher than the values for alternative systems (Nimmo et al., 1993).

- The University of Texas at Austin has been developing an all-electric hybrid vapor-compression/desiccant air conditioner.

- AIL Research, Inc., is working on falling-film desiccant absorbers and advanced regenerators for next-generation liquid desiccant air conditioners.

- The Meckler Energy Group has been using the approach of integrating desiccant systems with conventional HVAC systems and cogeneration systems. Meckler has developed an integrated desiccant cold-air distribution system which allows for significant reductions in building's return ductwork and in energy costs (Meckler, 1989). In another study, Meckler has shown that desiccant-assisted ductless split HVAC systems are viable alternatives for small office buildings and could save energy costs (Meckler, 1994).

- New Thermal Technology, Incorporated, with support from the Florida Power Corporation, has been using desiccant systems integrated with standard vapor-compression units for restaurant application, taking heat for regeneration from condenser coils and solar collectors. The goal of the system is to reduce peak demand.
- The National Renewable Energy Laboratory (NREL), with U.S. Department of Energy support, is examining lowtemperature desiccants for solar cooling applications; however, the work can also be extended to electric applications with waste heat-recovery. NREL and the Meckler Energy Group, with funding from GRI, have studied a liquid-desiccant-enhanced heat-pipe unit for preconditioning ventilation air. Initial test results indicated that this approach could result in a efficient preconditioner.

\section{CONCLUDING REMARKS}

Desiccant dehumidification is an established technology that has been used successfully for many years in institutional and industrial applications. Commercial applications are now gaining acceptance. Desiccant systems have been applied successfully in supermarkets and ice rinks. Hotels and motels, office buildings, and restaurants provide the next opportunity.

Lowering the cost of desiccant dehumidification systems and improving their performance will clearly provide more opportunities for desiccant dehumidification technology. Currently, a number of cost-effective applications in the market will result in increased sales during the next several years; but as in other technologies, further $R \& D$ and demonstration programs will enhance broader applications of the technology. Lowtemperature desiccants can effectively use waste heat from electric air conditioners and improve their efficiency and effectiveness-an area that utilities and EPRI need to participate for further development. Desiccant dehumidification systems as add-on modules to electrical refrigeration systems could help solve the challenges facing the HVAC industry in the 1990s: increased ventilation rates, need for improved indoor air quality and better humidity controls, phase-out of CFCs, national standards requiring higher efficiency for cooling systems, and desire for lowered peak electric demands. These factors, and the ability for desiccant systems to solve specific problems, are driving these desiccant technologies to the mainstream of the air-conditioning market.

Disclaimer: The products, concepts, and organizations mentioned in this paper are given as examples. The author does not endorse any of them. There are a number of other products, concepts, and organizations that could have been presented. 


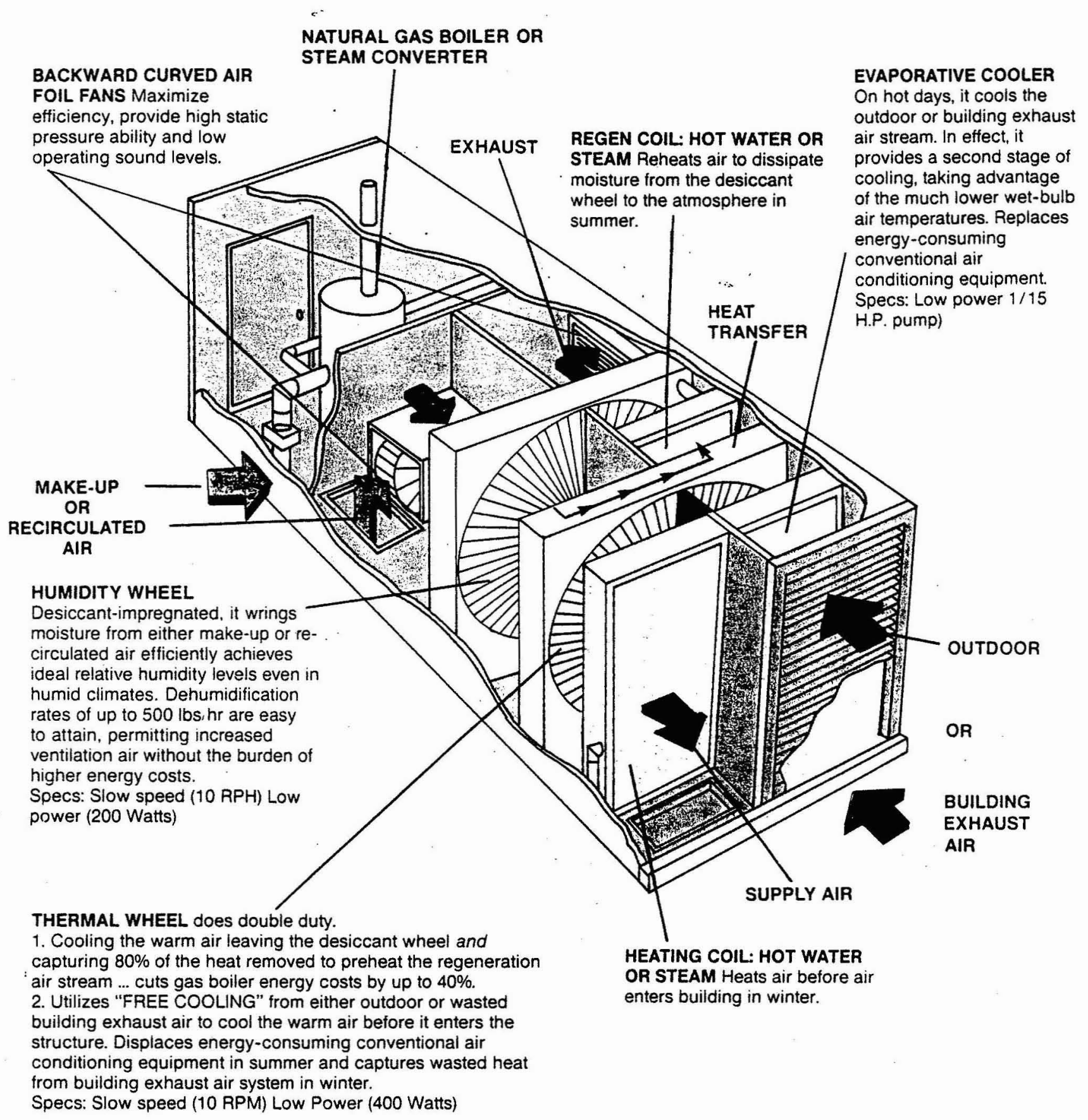

Figure 9. ICC Technologies DESI/AIR System 


\section{REFERENCES}

AGCC, March/April 1994, "Hot on Desiccants," Cool Times, Vol. 5, No. 2, pp. 18-20, American Gas Cooling Center, Arlington, VA.

American Hotel and Motel Association, 1991, Survey of Mold and Mildew in Hotels and Motels, New York, NY.

ASHRAE, 1992, Desiccant Cooling and Dehumidification, Special Publication, American Society of Heating, Refrigerating, and Air Conditioning Engineers, Atlanta, GA.

Banks, N.J., 1992, "Field Test os a Desiccant-Based HVAC System for Hotels," ASHRAE Transactions, Vol. 98, Pt. 1, pp. 1303-1310.

EPRI, August 1992, Assessment of Gas and Electric Cooling Equipment, EPRI TR-101142, Electric Power Research Institute, Palo Alto, CA.

GRI, 1994, "SuperAire Systems Applications," PaceSetters, 3194 GND 10,000, Gas Research Institute, Chicago, IL.

GRI, December 1992, "Dehumidification-A Major Opportunity for Natural Gas," GRI Technology Focus, Gas Research Institute, Chicago, IL.

Harriman, L.G., III, 1990, The Dehumidification Handbook, 2nd Edition, Munters Cargocaire, Amesbury, MA.

Harriman, L.G., III, January 1994, "Field Experience with

Desiccant Systems," Engineered Systems, pp. 63-68.

ICC Technologies, Inc., DESI/AIR Product Literature, Philadelphia, PA.

Meckler G., March 1993, "Integrated IAQ-CFC Retrofit

Saves Energy," Consulting-Specifying Engineer, pp. 42-48.

Meckler, M., 1994, "Comparing Conventional and DesiccantAssisted Ductless Split HVAC Systems for Offices in Several U.S. Cities," ASME Solar Energy Conference Proceedings, San Francisco, CA, March 27-30, 1994.

Meckler, M., May 1989, "Integrated Desiccant Cold Air Distribution," Heating/Piping/Air Conditioning, pp. 67-127.

Munters Cargocaire, Dehumidifiers Product Literature, Amesbury, MA.

Munters DryCool, The SuperAire System Product Literature, Selma, TX.

Nimmo, B.G., R.K., Collier, and K. Rengarajan, 1993, "DEAC: Desiccant Enhancement of Cooling-Based Dehumidification," ASHRAE Transactions, Vol. 99, Pt. 1, pp. 842-848.

Pesaran, A.A., T.R. Penny, and A.W. Czanderna, October 1992, Desiccant Cooling: State-of-the-Art Assessment, NREL/TP254-4147, National Renewable Energy Laboratory, Golden, CO. 